\title{
Role of Ileostomy in Advanced Cases of Typhoid Perforation
}

\author{
L MAQSOOD F MUMTAZ \\ Department of Surgery, King Edward Medical College/Mayo Hospital, Lahore \\ Correspondence to Dr. Fawad Mumtaz, Assistant Professor Surgery
}

\begin{abstract}
A study of 72 cases with typhoid perforation is presented. All the cases included in the study had more than $48 \mathrm{hrs}$ peritonitis with highly inflamed gut and presented late with septic shock. They were treated with exteriorization of the perforation as ileostomy. Postoperative recovery was satisfactory with minimal complications and very few mortalities. The ileostomy was closed 2 months later in all the cases.
\end{abstract}

Key words: Typhoid perforation, ileostomy.

Typhoid fever is a persistent global health problem with a devastating socioeconomic impact on the developing countries of the world. Its incidence is higher in developing countries where feeding habits and water supply are not hygienic. Intestinal perforation is one of the most lethal complications of typhoid fever. The disease is more common in summer season. The usual victims are young adults at the beginning of their economically producing years.

As most of the patients come from periphery where they are treated for long time by quacks, they turn up in a well-advanced state of peritonitis with toxemia, dehydration, electrolyte imbalance and gross malnutrition. Surgical intervention along with antibiotic therapy is the standard treatment for typhoid perforation. Postoperative complications of typhoid perforation are well known.

The purpose of our study was to determine the role of ileostomy in advanced cases of typhoid perforation by which the high mortality and morbidity could be reduced.

\section{Material and method:}

Seventy-two patients with advanced peritonitis due to typhoid perforation who presented to the Emergency of South Surgical Unit of Mayo Hospital between November 2002 to November 2004 were included in this study. Inclusion criteria were set to include only the patients with advanced peritonitis of more than 48 hours, very toxic patients and in whom per-operatively the state of the gut was not healthy. On admission the patients were resuscitated with I/V fluids, pre-operative antibiotics were given, N.G. tube and Folley's catheter were passed and blood was arranged.

After proper resuscitation laparotomy was done through midline incision. Pus was drained and thorough peritoneal lavage was done; Margins of the perforation were debrided and the perforation was exteriorized as loop ileostomy in right iliac fossa.

Post operatively the patients were put on drip and suction, antibiotic therapy i.e., chloramphenicol/ quinolones and metronidazole, $\mathrm{H}_{2}$ receptor antagonist and analgesia.

Stepwise oral intake was started when the ileostomy started working and discharged if uneventful. Complications were dealt on merit.

\section{Results}

Seventy two patients were included in the study. They were between $14-50$ years of age. $46(63.8 \%)$ patients were male and $26(36.2 \%)$ were female. The time interval between the onset of symptoms and peritonitis varied between 1-8 days. Most common symptoms were fever $(100 \%)$, vomiting $(82 \%)$, abdominal pain $(100 \%)$ and constipation $(95 \%)$. The signs were abdominal tenderness $(100 \%)$ and distension $(86 \%)$. Routine investigations i.e., blood $\mathrm{C} / \mathrm{E}$, serum electrolytes, blood sugar, urea were done in all the patients. On erect X-ray abdomen, free gas under the diaphragm was present in $90 \%$ of cases. Widal test was positive in $75 \%$ of cases. In $68(94.4 \%)$ patients there was a single perforation at the antemesenteric border of distal ileum. In 4(5.5\%) patients there were 2 perforations. Loop ileostomy was done in all these patients in right iliac fossa. Abdomen was closed with prolene no. 1 as mass closure and the skin wound was left open. Ileostomy bag was applied on the $2^{\text {nd }}$ day. Various post op complications were wound sepsis in $23(31.9 \%)$ patients, wound dehiscence $5(6.9 \%)$, stress bleed $2(2.7 \%)$, intra-abdominal abscess 9 $(12.5 \%)$, ileostomy excoriation $8(11.1 \%)$, ileostomy prolapse $3(4.1 \%)$, postop adhesions $5(6.9 \%)$, death 3 (4.1\%).

\section{Discussion:}

Typhoid fever is caused by Salmonella Typhi. The typhoid bacilli get entry into the body by ingestion of food or water contaminated with infected feces or urine. Its incidence is higher in developing countries where feeding habits and water supply are not very hygienic ${ }^{1}$.

The intestinal perforation is one of the most lethal complications of this disease $\mathrm{e}^{2}$. The disease is associated with very high mortality and morbidity on its own and when it is complicated with intestinal perforation it becomes extremely high. The use of steroids by quacks to reduce the fever quickly further aggravates the problem. In literature the incidence of typhoid perforation of intestine varies widely. Some authors have reported the frequency of $0.5 \%^{3}$ and $4 \%{ }^{4}$ respectively. While Olurin ${ }^{5}$ et al reported the incidence as $33 \%$. However these figures merely indicate the frequency of detectable cases of perforation proved by operation. They do not by any means represent the actual frequency of perforation in 
typhoid patients. Maximum incidence of perforation in our series is in the age group of $14-50$ years

The males are affected more commonly as reported by Khan and $\mathrm{Misra}^{6}$, which corresponds to our series. In endemic areas the diagnosis of typhoid perforation can usually be made without difficulty. There is history of fever extending over a period of one to four weeks and culminating in the acute picture of enteric perforation. Serological and bacteriological confirmation requires a delay of one to 3 days before therapy is instituted. Our policy has been to begin with vigorous resuscitation with I/V fluids N.G suction, antibiotics and to proceed to laparotomy. More over the Widal test in not positive in all the cases $^{7}$ in our series.

Plain X-ray abdomen in erect posture revealed gas under diaphragm in $60(90 \%)$ patients in our series. This is in contrast to $68 \%$ of cases having gas under diaphragm in a series conducted by $\mathrm{Ajao}^{8}$.

Treatment of uncomplicated typhoid fever is medical but once the complication of ileal perforation has occurred surgical intervention becomes mandatory. By surgical treatment, not only is the purulent material removed by adequate peritoneal lavage but also further leakage of intestines is avoided.

So many surgical procedures have been described by different workers starting from simple closure to complex resection of gut. In our series 72 cases were treated by constructing loop ileostomy. In 68 patients with single perforation, ileal perforation was exteriorized as ileostomy. This is comparable to Beniwal ${ }^{9}$ et al who found a single perforation in $81.4 \%$ of pts. This was easily managed as perforation was away from ileo-cecal junction. In remaining patients, there were multiple perforations so distal perforation was repaired with vicryl $2 / 0$ and proximal perforation was exteriorized as ileostomy. This was contradictory to $\mathrm{M}$. Ashraf $\mathrm{Khan}^{10}$ et al who repaired all perforations and did proximal ileostomy. Our results are encouraging with only $4.1 \%$ mortality. A series of 42 patients with typhoid perforation was presented by Singh ${ }^{11}$ et al in which simple closure with proximal ileostomy was found to be the best procedure with regard to morbidity and mortality. In our series all these patients were severely toxic, moribund. 2 of them died of sever chest infection on $5^{\text {th }}$ day. $3^{\text {rd }}$ patient never came out of anesthesia and was put on ventilator and died later. One thing is to be kept in mind that all our patients were severely toxic with advanced peritonitis in which perforation was more than $48 \mathrm{hrs}$ duration, because we had already excluded the patients with early peritonitis and healthy gut.

In conclusion typhoid perforations continue to have high morbidity and mortality. Although simple closure of the perforation may be done in the patients who present with perforation earlier, the procedure of choice for the patients who present with longer duration of peritonitis is ileostomy which carries significantly low morbidity and mortality.

Table 1

\begin{tabular}{lll}
\hline Complications & $=\mathrm{n}$ & \%age \\
\hline Wound Sepsis & 23 & 31.9 \\
Wound dehiscence & 5 & 6.9 \\
Chest infection & 15 & 20.8 \\
Stress bleed & 2 & 2.7 \\
Intra-abdominal abscess & 9 & 12.5 \\
Ileostomy excoriation & 8 & 11.1 \\
Ileostomy prolapse & 3 & 4.1 \\
Post-op adhesions & 5 & 6.9 \\
Death & 3 & 4.1 \\
\hline
\end{tabular}

\section{References:}

1. Samantray SK, Jobson SC, Chakrabarti AK. Enteric fever An analysis of 500 cases. Practitioner 1973:218:400-05

2. Kim KP, Oh SK, Jarret E. Management of ileal perforation due to typhoid fever. Amm Surg 1975; 181: 88-91

3. Bitar, Tarpley: Intestinal perforation in typhoid fever: A historical and state if the art review Rev Infec Dis 1985; 7:258-71.

4. Keenan JP, Haddley GP. The surgical management of typhoid perfortaion in children Br J Surg 1984;71:928-9.

5. Olurin EO, Ajayi OO, Bohrer SP. Typhoid perforation JR Cole Surg Edin 1972; 17:353-63

6. Khana AK, Misra MK. Typhoid perforation of the gut. Postgrad Med J 1984; 60:523-9

7. Shri DM Harish CG Arun T, Brahm DS. Typhoid bowel perforation: A review of 264 cases. Int surg 1984; 69:155-8

8. Ajao OG; typhoid perforation: factors affecting mortality and morbidity. Int Surg 1982; 67:317-9

9. Beniwal U, Jindal D, Sharma J, Jain S, Shyam G. Comparative study of operative procedures in typhoid perforation. Indian J Surg 2003; 65:172-177

10. M. Ashraf Khan, Gulzar Ahmad, Naveed Iqbal. Role of ileostomy in typhoid perforation J Srug 1996 vol 11\&12.

11. Singh KP, Singh K, Kohli JS. Choice of Surgical procedure in typhoid perforation; Experience in 42 cases $\mathrm{J}$ Ind Med Asso. 1991; 89(9); 255-6. 